Santa Clara University

Scholar Commons

Psychology

College of Arts \& Sciences

6-29-2007

\title{
Are successful applicants to the Roman Catholic deaconate psychologically healthy?
}

Thomas G. Plante

SantaClara University, tplante@scu.edu

Kathleen Lackey

Follow this and additional works at: http://scholarcommons.scu.edu/psych

Part of the Psychology Commons

\section{Recommended Citation}

Plante, T. G. \& Lackey, K. (2007). Are successful applicants to the Roman Catholic deaconate psychologically healthy? Pastoral Psychology, 55, 789-795.

The final publication is available at Springer via http://doi.org/10.1007/s11089-007-0081-2

This Article is brought to you for free and open access by the College of Arts \& Sciences at Scholar Commons. It has been accepted for inclusion in Psychology by an authorized administrator of Scholar Commons. For more information, please contact rscroggin@scu.edu. 


\section{Are Successful Applicants to the Deaconate Psychologically Healthy? \\ Thomas G. Plante ${ }^{1,2}$, Katy Lackey}

The current investigation evaluated psychological and personality profiles of successful applicants to the deaconate in several Roman Catholic dioceases in California. The MMPI-2 and 16PF were administered to 25 applicants between 2004-2006 who subsequently entered the permanent deaconate program. Results indicate that these applicants to the deaconate were generally well-adjusted as well as being socially responsible. Findings also suggest some tendency for defensiveness, repression, naievete, and a strong need for affection.

The Roman Catholic Church has experienced a steady and consistent decline in the number of priests ordained and in ministry in the United States during recent decades. Yet, the number of Catholics in America and elsewhere continues to grow. One study has suggested a fairly rapid decline in the number of priests with a 45-65\% reduction (Schoenherr, Young, \& Vilarino, 1988). The Center for Applied Research in the Apostolate (CARA) reports that in 1965 there were approximately 45.6 million Catholics and 58,632 priests in the United States. Forty years later, in 2005, there were 64.8 million Catholics and only 42,839 priests in America (CARA, 2006). Astonishingly, in the 1980s there was almost one priest per 1,000 Catholics in the United States, whereas today, the ratio is about one priest for every 2,200 Catholics (Cozzens, 2000). A multitude of factors account for this crisis including fewer persons interested in living a life of poverty, obedience, and chastity during modern times (Cozzens, 2000). Regardless of current and future trends, the number of Catholics continue to grow while the 
number of priests persistently decreases, and there remains an emerging crisis for someone to perform priestly functions.

One promising way to cope with the declining number of priests is the increased ordination of permanent deacons. Diakonia, the Greek root of the word "deacon," translates as "service" (Dix, 2005). The specific role of a deacon often depends upon the traditions and desires of the local bishop. Deacons, who can be married, can serve the Church in a large number of activities and ministries including presiding over weddings, funerals, and baptisms as well as leading many other activities and ministries often conducted by priests. Deacons frequently assist during Mass by reading the gospel or performing prayer rituals (Dix, 2005). A recent survey on deacons in the United States found that $99 \%$ of them assist at Masses with $84 \%$ doing this at least once a week (Gary \& Gautier, 2004). Furthermore, 96\% of deacons preside over baptisms while $95 \%$ do so at funeral and wake services (Gary \& Gautier, 2004). They also often take part in the celebration of the Eucharist as well as preaching (Dix, 2005). They frequently bring communion to the sick and dying as well (Dix, 2005). Duties not permitted by deacons include independently saying Mass and anointing the sick (Dix, 2005).

Remarkably, no empirical research has been conducted on the psychological profiles or personality characteristics of permanent deacons in the Roman Catholic Church. Yet this information is crucial because, as the need to fill the roles previously held by priests continues to rise, the Church must find psychologically healthy applicants to do so. A number of studies have been published that have examined these variables among priests. These studies and findings can be used to both model and compare the psychological health of successful deaconate applicants. As people often apply to be priests and deacons for the similar reasons-to serve the Church, both laity and God-we expect to find useful parallel results between these two groups. 
Our previous studies reveal that, in general, successful applicants to the priesthood tend to be well-adjusted and psychologically healthy. This is indicated in particularly low scores on scales that demonstrated psychopathology (Plante, Aldridge, \& Louie, 2005). However, successful priest applicants do tend to score high on defensiveness and repression as well as social responsibility and intelligence (Plante et al, 2005).

The purpose of the current study was to investigate the personality and psychological functioning of recent candidates to the deaconate from several Roman Catholic dioceases in California. An examination of psychological profiles relative to national norms was conducted to investigate the general psychological and personality health of these men. 


\section{METHODS}

\section{Subjects}

Twenty-five successful applicants to the deaconate from several dioceases in California were utilized as research participants (Mean age $=51.68, \underline{\mathrm{SD}}=8.84$, range 37 to 64 years). Of these applicants, sixteen were born in the United States, two in Mexico, three in Vietnam, two in the Philipines, one in India, and one in Poland. Four applicants had never been married, while sixteen reported being currently married, one was divorced, and three were married more than once.

\section{Measurements}

The MMPI-2 (Hathaway \& McKinley, 1989) is the most commonly used and researched psychological self-report measure available. It includes 567 true-false items that comprise 3 validity scales, 10 basic clinical scales, and over 50 supplementary and additional subscales. The most recent edition is normed on 1980 U.S. Census figures. The questionnaire is considered highly reliable and valid.

The 16PF (Cattell, Cattell, \& Cattell, 1993) is a well researched personality questionnaire that consists of 185 multiple-choice items comprising 16 primary personality factor scales. Internal consistency reliabilities average about .74 with test-retest reliabilities averaging about .80 for two-week intervals, and about .70 for two-month intervals. The newest edition is normed on 1990 U.S. Census figures.

\section{Procedure}

The applicants completed the MMPI-2 and 16PF, as well as a one hour clinical interview prior to admission to the deaconate between 2004 and 2006. The psychological evaluation was 
conducted as one of the last procedures of the application process prior to admission. All results were converted to standard scores and entered onto a computer using SPSS-XIII.

\section{RESULTS}

Means and standard deviations for MMPI-2 scales and 16PF scores are provided in Tables 1 and 2 .

[Insert Tables 1 and 2 about Here]

\section{MMPI-2 Results}

Standardized T-scores from the applicants were compared to national norms using mean T-scores of 50 and standard deviations of 10 (Hathaway \& McKinley, 1989). A review of Table 1 indicates a variety of significant MMPI-2 findings when compared to these national norms. First, the applicants tend to be defensive with significant elevations on the MMPI-2 L $(\underline{\mathrm{M}}=$ $62.48, \underline{\mathrm{SD}}=13.81, \underline{\mathrm{p}}<.001), \mathrm{K}(\underline{\mathrm{M}}=62.40, \underline{\mathrm{SD}}=8.26, \underline{\mathrm{p}}<.001$, and $\mathrm{R}$ scales $(\mathrm{M}=56.96, \mathrm{SD}=$ 9.42, $\mathrm{p}<.01)$, and low scores on the F scale $(\underline{\mathrm{M}}=42.60, \underline{\mathrm{SD}}=4.66, \underline{\mathrm{p}}<.001)$. Second, subjects tend to score high on social responsibility (Scale Re: $\underline{\mathrm{M}}=58.64, \underline{\mathrm{SD}}=6.07, \underline{\mathrm{p}}<.001$ ). Third, subjects also tend to show a higher need for affection (Scale Hy2: $\underline{\mathrm{M}}=60.84, \underline{\mathrm{SD}}=10.03, \underline{\mathrm{p}}$ $<.001$ ), as well as naivete (Scale PA3: $\underline{\mathrm{M}}=57.84, \underline{\mathrm{SD}}=7.24, \underline{\mathrm{p}}<.001$ ), strong ego strength (Scale $\mathrm{ES}: \mathrm{M}=55.40, \mathrm{SD}=5.61, \mathrm{p}<.001)$, and imperturbability $($ Scale MA3: $\underline{\mathrm{M}}=57.80, \underline{\mathrm{SD}}=6.93, \underline{\mathrm{p}}<$ .001). Finally, subjects tend to show generally good adjustment with significantly low scores on a wide variety of clinical measures, as compared to national norms.

It is important to note the most elevated findings that may have more clinical significance. For example, the highest mean elevations with scaled scores at or above 60 included measures of defensiveness (i.e., K Scale and L Scale). Examining scores above 65, 
which the MMPI-2 considers clinically significant, found that the most frequent scores that were above 65 were found on the L scale (occurring among 14 of the 25 applicants representing $56 \%$ of the group), and the K and HY2 scales (both occurring among 11 of the 25 applicants representing 44\% of the population). A composite MMPI-2 profile can be found in Figures 1. [Insert Figure 1 about Here]

\section{PF Results}

Sten scores from the subjects were compared to national norms using mean sten scores of 5.5 and standard deviations of 3 (Cattell, Cattell, \& Cattell, 1993). A review of Table 2 indicates a variety of significant $16 \mathrm{PF}$ findings when compared to these national norms. Subjects tend to be bright (Scale B: $\underline{\mathrm{M}}=6.56, \underline{\mathrm{SD}}=1.89, \underline{\mathrm{p}}<.05$ ), warm and attentive (Scale A: $\underline{\mathrm{M}}: 6.44, \underline{\mathrm{SD}}=1.45, \underline{\mathrm{p}}<.01)$, emotionally stable (Scale $\mathrm{C}: \mathrm{M}=6.20, \mathrm{SD}=1.66, \mathrm{p}<.05)$, and socially bold (Scale H: $\underline{\mathrm{M}}=6.36, \underline{\mathrm{SD}}=1.58, \underline{\mathrm{p}}<.05$ ). In addition, subjects were found to be cooperative (Scale $\mathrm{E}: \mathrm{M}=4.84, \mathrm{SD}=1.21, \mathrm{p}<.05)$, trusting (Scale $\mathrm{L}: \mathrm{M}=4.44, \mathrm{SD}=1.96, \mathrm{p}<.05)$, genuine (Scale N: $\mathrm{M}=4.48, \mathrm{SD}=1.39, \mathrm{p}<.01$ ), relaxed (Scale Q4: $\mathrm{M}=4.60, \mathrm{SD}=1.44, \mathrm{p}<.01$ ). A composite $16 \mathrm{PF}$ profile can be found in Figure 2.

Elevated findings on both the high and low ends, either 7 and above or 3 and below, suggest clinical significance. The highest elevated scores were found in measuring reasoning (Scale B), with significant scores occurring in 15 of the 25 applicants or $60 \%$ of the sample. Another interesting finding were elevated scores in sensitivity (Scale I), with significant scores occurring in 12 of the 25 applicants, or $48 \%$ of the sample. Other highly elevated scores for 10 of the 25 or $40 \%$ of the applicants were found warmth and attentiveness (Scale A), emotional stability (Scale C), and were also found to be trusting (Scale L). 


\section{DISCUSSION}

Results from this investigation of 25 successful applicants to the deaconate suggest that these men are generally well-adjusted individuals. Findings suggest that these successful applicants are bright, socially responsible, and emotionally stable. However, results also suggest that they tend to maintain defensive (especially repressive) styles. These findings are particularly noteworthy as they reflect similar scores found among successful applicants to the priesthood. For instance, this study found that the mean score for the MMPI K scale among successful applicants to the deaconate was 62.40 , comparable to scores found among applicants to priesthood. Furthermore, successful applicants to the priesthood and deaconate of the Catholic Church both tended to be well-adjusted. This is evidenced in their generally high scores for brightness and social responsibility. Moreover, both groups demonstrated a lack of elevation on scales that indicate psychopathology. Interesting as well, is that results suggest that applicants for priesthood tend to score higher on defensiveness and repressive measures and need for affection than deacons in our current study (Plante et al, 2005). This study found this these measures to be higher for successful applicants to the deaconate as well, but to a lesser degree.

A variety of methodological issues suggest that these results must be viewed with caution. First, this study utilized a modest number of successful applicants from the deaconate in the Catholic Church without the benefits of control groups. Therefore, conclusions concerning the personality and psychological functioning of this group could be associated with a number of factors (e.g., education, social class, screening process prior to the psychological evaluation), in addition to their desire to enter the deaconate. Second, a number of analyses were conducted given the modest sample size which increases the chance of false positive or Type I errors. Finally, the defensive pattern that surfaced with this sample could be an artifact of the testing 
situation. All of the men completed psychological testing as part of the application procedure to enter the deaconate. Therefore, they likely wanted to present a highly favorable view of themselves in the context of the application process.

Overall, results suggest that successful applicants to the deaconate were generally welladjusted individuals. Results also suggest that defensiveness (especially repression) may be an issue for many. Further research regarding these issues is needed to better understand the personality and psychological functioning of Catholic clergy. Future research should utilize larger sample sizes and control conditions to better understand the psychological and personality functioning of clergy. During these challenging times for Catholic priests and the American Catholic Church in general, research is especially needed to assist both the Church and the general population in the hopes of developing better screening and selection measures for Catholic clergy. However, in the meantime, it appears that the answer to the question posed in the title of this paper, "Are successful applicants to the deaconate psychologically healthy?" is yes. 


\section{REFERENCES}

Center for Applied Research (2006). Frequently asked questions. Catholic Church statistics.

Center for Applied Research in the Apostolate, Georgetown University, Washington, D.C.:

Author

Cattell, R.B., Cattell, A.K., \& Cattell, H.E.P. (1993). Sixteen Personality Factors Questionnaire, Fifth Edition. Champaign, IL: Institute for Personality and Ability Testing.

Cozzens, D. (2000). The Changing Face of the Priesthood. The Liturgical Press; Collegeville, MN.

Dix, K. (April 2005). What's a Deacon to do? U.S. Catholic, 70, 47.

Gary, M. M, and Gautier, M. L. (January 2004). Profile of the diaconate in the United States: A report of findings from CARA's deacon poll (A report originally prepared for the secretariat for the diaconate of the United States conference of Catholic Bishops). Washington, D.C.; Center for Applied Research in the Apostolate, Georgetown University.

Hathaway, S. R. \& McKinley, J. C. (1989). Manual for the Minnesota Multiphasic Personality Inventory-2 ${ }^{\mathrm{TM}}\left(\mathrm{MMPI}-2^{\mathrm{TM}}\right)$. Minneapolis, MN: University of Minnesota Press.

Plante T.G., Aldridge A, Louie, C (2005). Are successful applicants to the priesthood psychologically healthy? Pastoral Psychology, 54, No. 1, pgs. 
Schoenherr, R. A., Young, L. A., Perez, V. J. (1988). Demographic transitions in religious organizations: A comparative study of priest decline in Roman Catholic diocese. Journal-for-theScientific-Study-of-Religion, 27, 499-523. 
Table 1. Means and standard deviations for MMPI-2 scores among successful Catholic clergy applicants

$\begin{array}{ccc}\text { Validity Measures } & \text { Means } & \text { Standard Deviations } \\ \text { L } & 62.48 & (13.81) \\ \text { F } & 42.60 & (4.66) \\ \text { K } & 62.40 & (8.26)\end{array}$

Clinical Scales

$\begin{array}{lll}\text { Hs } & 52.40 & (5.57) \\ \mathrm{D} & 49.60 & (7.88) \\ \mathrm{Hy} & 53.44 & (7.76) \\ \mathrm{Pd} & 51.16 & (6.31) \\ \mathrm{Mf} & 48.32 & (7.02) \\ \mathrm{Pa} & 50.24 & (6.50) \\ \mathrm{Pt} & 53.96 & (6.50) \\ \mathrm{Sc} & 50.16 & (5.50) \\ \mathrm{Ma} & 48.60 & (7.65) \\ \mathrm{Si} & 44.76 & (5.63)\end{array}$


Table 1, continued

Selected Supplementary and Content Scales

$\begin{array}{lll}\text { A } & 42.44 & (6.23) * * * \\ \text { R } & 56.96 & (9.42)^{* *} \\ \text { Es } & 55.40 & (5.61)^{* * *} \\ \text { Mac-R } & 45.04 & (6.49)^{* *} \\ \text { OH } & 40.41 & (7.17)^{* * *} \\ \text { Do } & 52.64 & (7.39) \\ \text { Re } & 58.64 & (6.07)^{* * *} \\ \text { Hy2 } & 60.84 & (10.03)^{* * *} \\ \text { PA3 } & 57.84 & (7.24)^{* * *} \\ \text { Ma3 } & 57.80 & (6.93)^{* * *}\end{array}$

$\wedge$ most significant elevations above 55 
Table 2. Means and standard deviations for 16PF Scores among successful Catholic clergy applicants

\begin{tabular}{|c|c|c|}
\hline Factors & Means & Standard Deviations \\
\hline A & 6.44 & $(1.45)^{* *}$ \\
\hline $\mathrm{B}$ & 6.56 & $(1.89)^{*}$ \\
\hline $\mathrm{C}$ & 6.20 & $(1.66)^{*}$ \\
\hline $\mathrm{E}$ & 4.84 & $(1.21)^{*}$ \\
\hline $\mathrm{F}$ & 4.44 & $(1.39)^{* *}$ \\
\hline $\mathrm{G}$ & 5.96 & $(1.59)$ \\
\hline $\mathrm{H}$ & 6.36 & $(1.58)^{*}$ \\
\hline I & 6.12 & (1.79) \\
\hline $\mathrm{L}$ & 4.44 & $(1.96)^{*}$ \\
\hline M & 4.88 & $(1.86)$ \\
\hline $\mathrm{N}$ & 4.48 & $(1.39)^{* *}$ \\
\hline $\mathrm{O}$ & 5.32 & $(1.31)$ \\
\hline Q1 & 5.96 & $(1.59)$ \\
\hline Q2 & 5.32 & (1.93) \\
\hline Q3 & 5.00 & $(1.32)$ \\
\hline Q4 & 4.6 & $(1.44)^{* *}$ \\
\hline
\end{tabular}

